\title{
Effectiveness of virtual reality technology on functional mobility of older adults: systematic review and meta-analysis
}

\author{
Ana Isabel Corregidor-Sánchez' '*, Antonio Segura-Fragoso', Marta Rodríguez-Hernández', \\ Concepción Jiménez-Rojas'², Begoña Polonio-López' , JuAn José Criado-Álvarez I,3 \\ 'Faculty of Health Sciences, University of Castilla-La Mancha (UCLM), Talavera de la Reina, Toledo, Spain \\ ${ }^{2}$ Department of Geriatric Medicine, Hospital Central de la Cruz Roja Madrid, Spain \\ ${ }^{3}$ Institute of Health Sciences of Castilla-La Mancha Toledo Spain
}

Address correspondence to: Ana Isabel Corregidor-Sánchez, Faculty of Science and Health, University of Castilla-La Mancha, Avenida Real Fábrica de las Sedas, s/n 45600 Talavera de la Reina, Toledo, España. Tel: +34-63079308 I; Fax: +34-902 204 I30; Email:anaisabel.corregidor@uclm.es

\begin{abstract}
Background: The accessibility, versatility and motivation provided by virtual reality technology (VRT) have fostered its rapid expansion as a rehabilitation technique to improve functional mobility. The aim of this study was to investigate the effectiveness of rehabilitation programmes using VRT, specific virtual reality technology (VRT-S) and non-specific virtual reality technology (VRT-NS), to improve functional mobility in individuals aged $>60$ years versus conventional treatment (CT) or no intervention.

Methods: Nine databases (Cochrane Library, Scopus, PEDro, Medline, CSIC, Web of Science, OT Seeker, NGCH and CINAHL) were searched to identify randomised trials up to December 2019. Results of clinical trials that used VRT-S and VRT-NS in rehabilitation were combined, using a random effects model with inverse variance weighting of the studies. GRADE was used to assess the quality of evidence. The protocol was registered in PROSPERO: CRD42019131630. Overall, there was moderate quality of evidence for the functional mobility results, which means that the estimate of effect is likely to change.

Results: Sixteen of the 18 studies selected $(n=568)$ provided data for the subgroup meta-analysis. VRT-NS was more effective in improving functional mobility than no intervention [standardised mean difference (SMD) $=-1.02 ; 95 \%$ confidence interval (CI) $-1,91$ to $-0,14)$. VRT-NS was also more effective than CT in improving resistance in ambulation $(\mathrm{SMD}=-1.20 ; 95 \% \mathrm{CI}-1.93$ to 0.46$)$. No significant differences were found between VRT-S and CT or no intervention. Programmes in which $>18$ sessions were applied were more beneficial $(\mathrm{SMD}=-0.89 ; 95 \% \mathrm{CI}-1.71$ to $-0.08 ;<0.001$ ) than programmes with $\leq 18$ sessions ( $\mathrm{SMD}=0.04 ; 95 \% \mathrm{CI}-0.51$ to 0.59 ) versus no intervention.

Conclusions: Our results suggest that VRT is an effective intervention for improving functional mobility in older persons compared with CT. VRT-NS proved to be more effective than VRT-S. However, these results are still not conclusive due to the low methodological quality of the studies. Thus, new studies and analyses are required.
\end{abstract}

Keywords: virtual reality, exergame, rehabilitation, game technology, functional mobility, older people, game-based interventions

\section{Key points}

- Virtual reality technology (VRT) improved gait quality and resistance in healthy older people, which could be useful to prevent a decline in functional mobility.

- The application of VRT for $>18$ sessions may help to improve functional mobility in older persons.

- The quality of evidence was generally low. VRT-NS (exergames and virtual reality games) appeared to be more effective, but quality of evidence for VRT-S was higher (virtureality software specific for rehabilitation). 


\section{A. I. Corregidor-Sánchez et al.}

\section{Introduction}

The ageing process and its associated diseases can have a negative impact on the maintenance of motor skills necessary for mobility, which results in a decline of involvement in the community, an increase in the need for assistance and a decline in quality of life $[1,2,3]$. Walking, standing and sitting are central elements of functional mobility [4] and have been identified as a priority in care and rehabilitation plans for older persons $[5,6]$.

Preventing functional impairment requires a proactive approach to functional mobility rather than reactive approaches after motor deficits have appeared and falls have occurred. Early intervention in older adults without functional impairment can slow their decline, maintain the function and quality of life for a longer time and lower the costs of care for dependency $[7,8]$. Therefore, there is a need for better preventive strategies to maintain the independence of the healthy older adult.

There has been growing interest over the last decade in the potential of virtual reality technology (VRT) for the promotion of and adherence to physical exercise [9, 10, $11]$, rehabilitation of motor skills $[12,13,14,15]$ and fall prevention $[16,17,18,19]$. There are two types of VRT [20]: (i) specific virtual reality-based technology (VRT-S), designed for use in clinical rehabilitation programmes; and (ii) interactive videogames or virtual reality exergames (Nintendo Wii ${ }^{\circledR}$, Xbox ${ }^{\circledR}$, Play Station ${ }^{\circledR}$ and Xavi Sport ${ }^{\circledR}$ ) from the entertainment industry constituting non-specific virtual reality-based technology (VRT-NS). VRT-S allows adaptation of the activity to each person and collects kinematic information from each joint. VRT-NS presents standardized game levels and the information collected is only the score in the game.

Recent systematic reviews and meta-analyses have assessed the effectiveness of VRT in improving functional mobility in older adults. Booth [25] found benefits in favour of VRT in adults with balance problems, although these results were not conclusive. A later review [26] compared VRT with balance training programmes and with control groups with no intervention, and found that VRT was superior to no intervention but slightly inferior to balance programmes. However, Neri's results [27] proved that VRT was more effective than a conventional intervention in improving balance, ambulation and fear of falling, if the intervention exceeded 3-6 and 8-12 weeks. The latest published meta-analytical data [28] reveal that VRT can improve static balance and sensory-motor integration, without significant differences in dynamic balance and gait speed when compared with conventional therapy. The discrepancies found may be due to the fact that none of the previous reviews has differentiated and compared the effects of the different types of VRT on functional mobility. Differentiating the use of the different VRT equipment is fundamental in order to dermine the real effectiveness of each of them compared with conventional therapy. Therefore, the aim of this meta-analytic review is to compare the effectiveness of the two types of VRT
(VRT-S and VRT-NS) versus conventional or no therapy, and the duration of treatment on functional mobility in community-dwelling people aged over 60 years.

\section{Methods}

The PRISMA (Preferred Reporting Items for Systematic Reviews and Meta-Analyses) statement was employed to report this review [35]. The GRADE (Grading of Recommendations Assessment, Development and Evaluation) system [21] was used to assess the quality of evidence. The protocol was registered in PROSPERO: CRD42019131630.

\section{Search strategy}

The search strategy was designed by an information scientist. We performed electronic searches in nine databases: Cochrane Central Register of Controlled Trials (CENTRAL), Scopus, PeDRO, Medline, databases of the Spanish National Research Council (CSIC), Web Of Science, OT Seeker, Guideline National Clearing House and CINAHL, from their inception up to December 2019. The search was not restricted to any specific language. Authors were contacted to retrieve non-reported data. Search strategies are shown in Appendix 1.

\section{Types of interventions}

Interventions with semi-immersive VRT aimed at improving functional mobility were the studies of interest. The use of video game consoles with exergames (VRT-NS) and virtual reality equipment designed specifically for rehabilitation programmes (VRT-S) were selected.

Functional mobility was defined according to the ICFWHO [22] as the ability to move from one position or place to another.

\section{Types of comparators and results}

The comparison group could be any other functional mobility intervention technique that included physical activity or physical exercise, according to the WHO definition of physical activity and physical exercise [23]: specific balance, endurance and/or aerobic exercises, performing activities of daily living or general mobility programmes, or no intervention at all.

\section{Types of studies and data extraction}

Only randomized controlled trials (RCTs) were selected. Studies were excluded if they (i) used VRT only for assessment; (ii) did not report results on functional mobility; or (iii) targeted older adults with neurological (stroke, Parkinson's or dementia) or other types of diseases that severely affected functional independence.

Two independent reviewers selected the studies and extracted the relevant data. Discrepancies were resolved by a third reviewer. Information was extracted regarding design, 
study objectives, participant characteristics, type of VRT, intervention (intensity, duration and frequency) and results.

\section{Assessment of risk of bias in the individual studies}

Two independent reviewers assessed the methodological quality of the studies using the items included in RevMan [24]: random sequence generation; allocation concealment; blinding of outcome assessment; incomplete outcome data; and selective reporting. These items were categorized as 'high', 'low' or 'unclear' according to the Cochrane Collaboration's tool for assessing the risk of bias [25]. When these items were clearly described and the articles were appropriate, they were classified as low risk of bias, when they were missing or inadequate they were classified as high risk of bias, and as unclear when they were not clearly described or data were missing from the text. When data were missing or reviewers needed clarifications, authors were contacted by Email. If after that the requested information was not obtained, the specific item was scored as 'unclear'.

\section{Summary measures and statistical analysis}

To initiate the meta-analysis, characteristics of the participants, types of VRT, number of sessions and level of bias were compared. Outcome measures such as the Timed up and Go (TUG) test and 6 min walking test (6MWT) were compared to assess the effectiveness of VRT on functional mobility. The standardised mean difference (SMD) represents the magnitude of the effect of the VRT intervention in each study with the variability that has been observed. The overall effect size weighted by the sample size of the studies was calculated, using the inverse variance method, and a random effects model if $P>10$ and a fixed model if $P>10$. The $95 \%$ confidence interval (CI) and statistical significance were calculated using the z-test. Software Review Manager 5.3.5 was used. To examine the effect of each study, a sensitivity analysis was carried out (Appendix 2). The magnitude of the effect was interpreted using Cohen's criteria for pooled estimates, considering a value of 0.8 as a large effect [26]. We used the $\chi^{2}$ test to calculate the statistical significance of the difference between subgroups.

\section{Publication bias}

Publication bias was assessed using the funnel plot created with RevMan and complemented with the DOI plot created with METAXL. Egger's method [27], Begg's test with Epidat 3.1 [28] and the Luis Furuyama-Kanamori index (LFK) [29] were used. An LFK index $\leq 1$ was interpreted as nonasymmetry, $>1 \leq 2$ as minor asymmetry and $>2$ as major asymmetry.

\section{Assessment of the level of evidence of the set of studies}

We used the GRADE system [21] considering five factors to assess the possible decrease of the level of evidence: (i) risk of bias of the set of studies; (ii) inconsistency; (iii) indirect evidence; (iv) imprecision by calculating the optimal information size (OIS); and (v) publication bias. We also considered three factors to assess the increase of the level of evidence: large magnitude of effect (SMD $>0.8)$, doseresponse gradient and no plausible confounders.

\section{Results}

\section{Selected studies}

We identified 2591 articles. After removing duplicates, 2282 articles were reviewed by title and abstract, selecting 79 manuscripts for complete reading. The review of the full text resulted in 18 studies. Two studies did not provide sufficient data to include in the analysis and further details have been sought from the authors (Appendix 3). The article selection process is summarised in the PRISMA flow diagram in Figure 1.

All studies were RCTs; Table 1 shows the main characteristics of the studies included (full version in Appendix 4). Five studies were carried out in the community [14, 30, $31,32,33,34]$, two trials in hospitals $[35,36]$ and nine trials were conducted in centres and nursing homes for older people $[13,15,34,37,38,39,40,41,42]$.

\section{Characteristics of participants and intervention}

The number of participants included in the meta-analysis was 568 , with a mean age of $60-96$ years, and $71 \%$ were women. In all except one of the trials [34], there was a higher percentage of women. The clinical profile of participants was characterized by walking independence, normal cognitive performance (MMSE >24), sufficient visual capacity to participate in rehabilitation sessions and no disability caused by neurological disorders, osteoarticular diseases, severe heart disease or brain injury.

All the studies applied VRT as the main intervention technique. Four of the 16 studies compared VRT with traditional rehabilitation $[17,35,37,40]$, two with activities of daily living $[12,34]$, four with health education programmes [15, $32,38,39$ ], one with cycling exercises [43] and six did not offer any intervention to the control group $[13,14,36,41$, 43, 44].

Only four studies [32, 33, 37, 42] used VRT-S; the rest of them applied VRT-NS with low-cost devicesmainly Nintendo Wii ${ }^{\circledR}$ and Sony Play Station ${ }^{\circledR}$. Functional mobility was trained with exergames such as Nintendo Wii $\mathrm{Fit}^{\circledR}{ }^{\circledR}$ and Nintendo Wii Sport ${ }^{\circledR}$. One study applied VRTNS without professional supervision [31], and none of the studies reported any relevant adverse effect. In general, the interventions were carried out by an occupational therapist or physiotherapist. The duration of the intervention ranged from 2 to 24 weeks. The number of sessions ranged from 10 to 84 , with a duration of between 20 and $50 \mathrm{~min}$. 


\section{A. I. Corregidor-Sánchez et al.}

Table I. Characteristics of included studies (abbreviated)

\begin{tabular}{|c|c|c|c|c|c|c|c|}
\hline Author & $\begin{array}{l}\text { Evidence level } \\
\text { Design }\end{array}$ & $n$ & $\begin{array}{l}\text { Age } \\
\text { (years) }(\mathrm{SD}), \\
\text { range }\end{array}$ & $\begin{array}{l}\text { Experimental } \\
\text { group }\end{array}$ & Control group & $\begin{array}{l}\text { Outcome } \\
\text { measures }\end{array}$ & Results \\
\hline $\begin{array}{l}\text { Crotty } 2011 \\
{[35]}\end{array}$ & Level I RCT & 44 & $\begin{array}{l}84(80-88) \\
79 \% \text { female }\end{array}$ & $\begin{array}{l}\text { Nintendo Wii } \\
5 \text { times/week }\end{array}$ & TSF & $\begin{array}{l}\text { TUG; BBS; } \\
\text { SPPB; FIM; } \\
\text { AIDL }\end{array}$ & $\begin{array}{l}\text { VRT-NS can improve mobility and } \\
\text { balance in comparison with traditional } \\
\text { approaches. }\end{array}$ \\
\hline $\begin{array}{l}\text { Daniel } 2012 \\
{[40]}\end{array}$ & Level I RCT & 23 & $\begin{array}{l}76(55-86) \\
57 \% \text { female }\end{array}$ & $\begin{array}{l}\text { Nintendo Wii } \\
\text { Fit } 15 \text { weeks }\end{array}$ & TSF & $\begin{array}{l}\text { SFT, } \\
\text { CHAMPS, } \\
\text { LLFDI SF-36. }\end{array}$ & $\begin{array}{l}\text { Both groups improve scores in } \mathrm{ABC} \\
\text { and CHAMPS scales. VRT-NS group } \\
\text { increases caloric expenditure. }\end{array}$ \\
\hline $\begin{array}{l}\text { Maillot } 2012 \\
{[41]}\end{array}$ & Level I RCT & 32 & $\begin{array}{l}71(65-78) \\
84 \% \text { female }\end{array}$ & $\begin{array}{l}\text { Nintendo Wii } \\
14 \text { weeks }\end{array}$ & $\begin{array}{l}\text { Without } \\
\text { intervention }\end{array}$ & $\begin{array}{l}\text { MAQ; GDS } \\
\text { MMSE }\end{array}$ & $\begin{array}{l}\text { Improvement in VRT-NS group in } \\
\text { cognitive and physical tests. There } \\
\text { were no differences in visuospatial } \\
\text { function. }\end{array}$ \\
\hline $\begin{array}{l}\text { Orsega- } 2012 \\
{[14]}\end{array}$ & Level I RCT & 30 & $\begin{array}{l}71(66-83) \\
92 \% \text { female }\end{array}$ & $\begin{array}{l}\text { Nintendo Wii } \\
4 \text { weeks }\end{array}$ & $\begin{array}{l}\text { Without } \\
\text { intervention }\end{array}$ & $\begin{array}{l}\text { ABC/FES; } \\
\text { ADL BBS; } \\
\text { TUG; CS }\end{array}$ & $\begin{array}{l}\text { VRT-NS group improved transfers, } \\
\text { balance and ADL. The control group } \\
\text { did not show any changes. }\end{array}$ \\
\hline $\begin{array}{l}\text { Pichierri } 2012 \\
\text { [56] }\end{array}$ & Level I RCT & 31 & $\begin{array}{l}85(81-91) \\
77 \% \text { female }\end{array}$ & $\begin{array}{l}\text { DDR Step } \\
12 \text { weeks }\end{array}$ & TSF & $\begin{array}{l}\text { PPA; FPA; } \\
\text { GAIT RITE; } \\
\text { FES }\end{array}$ & $\begin{array}{l}\text { VRT-S improves gait speed and } \\
\text { dual-task performance in comparison } \\
\text { with a traditional programme }\end{array}$ \\
\hline $\begin{array}{l}\text { Rendon } 2012 \\
{[13]}\end{array}$ & Level I RCT & 20 & $\begin{array}{l}84(60-95) \\
65 \% \text { female }\end{array}$ & $\begin{array}{l}\text { Nintendo Wii } \\
\text { Fit } 18 \text { weeks }\end{array}$ & $\begin{array}{l}\text { Without } \\
\text { intervention }\end{array}$ & $\begin{array}{l}\text { ABC; GDS; } \\
\text { 8FUG Test }\end{array}$ & $\begin{array}{l}\text { VRT-NS significantly improves } \\
\text { confidence in the activity and } \\
\text { functional mobility. No differences } \\
\text { were found in GDS scale. }\end{array}$ \\
\hline Lee 2013 [49] & Level I RCT & 64 & $\begin{array}{l}74(69-79) \\
71 \% \text { female }\end{array}$ & $\begin{array}{l}\text { Sony PS } \\
10 \text { weeks }\end{array}$ & $\begin{array}{l}\text { Health } \\
\text { education }\end{array}$ & $\begin{array}{l}\text { BBS; TUG; } \\
\text { STS Gait Rite; } \\
\text { FES }\end{array}$ & $\begin{array}{l}\text { VRT-NS can be used to prevent falls } \\
\text { and improve the quality of walking. }\end{array}$ \\
\hline $\begin{array}{l}\text { Schoene } 2013 \\
{[33]}\end{array}$ & Level I RCT & 37 & $77.5(73-82)$ & $\begin{array}{l}\text { Exergame } \\
\text { DDR } 8 \text { week }\end{array}$ & $\begin{array}{l}\text { Usual routine } \\
\text { Activities }\end{array}$ & $\begin{array}{l}\text { CSRT; CRST } \\
\text { MT; 5STS; } \\
\text { TUGFES; }\end{array}$ & $\begin{array}{l}\text { VRT-S is safe and can be applied at } \\
\text { home. It improves physical and } \\
\text { cognitive parameters for fall } \\
\text { prevention. }\end{array}$ \\
\hline $\begin{array}{l}\text { Singh } 2013 \\
{[17]}\end{array}$ & Level I RCT & 38 & $\begin{array}{l}62.5(58-69) \\
100 \% \text { female }\end{array}$ & $\begin{array}{l}\text { Nintendo Wii } \\
6 \text { weeks }\end{array}$ & TSF & $\begin{array}{l}\text { OPI; TST; } \\
\text { TUG }\end{array}$ & $\begin{array}{l}\text { VRT-NS improves agility, balance and } \\
\text { functional mobility. There was no } \\
\text { significant difference between groups. }\end{array}$ \\
\hline $\begin{array}{l}\text { Hughes } 2014 \\
{[32]}\end{array}$ & Level II RCT & 20 & $\begin{array}{l}77.4(72-83) \\
70 \% \text { female }\end{array}$ & $\begin{array}{l}\text { Nintendo Wii } \\
24 \text { weeks }\end{array}$ & $\begin{array}{l}\text { Without } \\
\text { intervention }\end{array}$ & $\begin{array}{l}\text { CAMCI; } \\
\text { CRSQ AIVD; } \\
\text { GAIT: } 6 \mathrm{~m}\end{array}$ & $\begin{array}{l}\text { VRT-NS group improved in overall } \\
\text { cognition, perceived cognitive ability } \\
\text { and gait speed. }\end{array}$ \\
\hline $\begin{array}{l}\text { Keogh } 2014 \\
{[12]}\end{array}$ & Level II & 34 & $\begin{array}{l}83(75-91) \\
55 \% \text { female }\end{array}$ & $\begin{array}{l}\text { Nintendo Wii } \\
8 \text { weeks }\end{array}$ & $\begin{array}{l}\text { Usual routine } \\
\text { activities }\end{array}$ & $\begin{array}{l}\text { FSST RAPA } \\
\text { WhOQOL- } \\
\text { BREF }\end{array}$ & $\begin{array}{l}\text { VRT-NS group showed a statistically } \\
\text { significant improvement of strength in } \\
\text { upper limbs, levels of physical, } \\
\text { psychological activity and quality of } \\
\text { life. }\end{array}$ \\
\hline $\begin{array}{l}\text { Chao } 2015 \\
\text { [39] }\end{array}$ & Level II & 32 & $\begin{array}{l}85(79-91) \\
67 \% \text { female }\end{array}$ & $\begin{array}{l}\text { SAHA + Wii } \\
4 \text { weeks }\end{array}$ & $\begin{array}{l}\text { Health } \\
\text { educational }\end{array}$ & $\begin{array}{l}\text { BBS; TUG } \\
\text { SMWT; GDS } \\
\text { FES; SF8 }\end{array}$ & $\begin{array}{l}\text { VRT-NS group improved gait speed, } \\
\text { reduced depressive symptoms and } \\
\text { increased confidence in ADL. Control } \\
\text { group did not show improvement in } \\
\text { any result. }\end{array}$ \\
\hline $\begin{array}{l}\text { Htut } 2018 \\
{[34]}\end{array}$ & Level I RCT & 84 & $\begin{array}{l}75(70-80) \\
37 \% \text { female }\end{array}$ & $\begin{array}{l}\text { Xbox-Kinect } \\
8 \text { weeks }\end{array}$ & $\begin{array}{l}\text { Without } \\
\text { intervention }\end{array}$ & $\begin{array}{l}\text { TUG; } 5 \text { TST, } \\
\text { FES; MoCA; } \\
\text { BBS }\end{array}$ & $\begin{array}{l}\text { VRT-NS group improved both } \\
\text { physical and cognition performance, } \\
\text { while the BE group was effective in } \\
\text { enhancing cognition. }\end{array}$ \\
\hline $\begin{array}{l}\text { Vieira } 2019 \\
{[15]}\end{array}$ & Level I RCT & 30 & $\begin{array}{l}84(78-90) \\
93 \% \text { female }\end{array}$ & $\begin{array}{l}\text { Nintendo Wii } \\
7 \text { weeks }\end{array}$ & $\begin{array}{l}\text { Health } \\
\text { educational }\end{array}$ & $\begin{array}{l}\text { FGA; MoCA; } \\
\text { FES }\end{array}$ & $\begin{array}{l}\text { VRT-NS was feasible, acceptable and } \\
\text { safe for frail older adults and improved } \\
\text { their postural control and gait. There } \\
\text { were no effects on cognition, mood or } \\
\text { fear of falling. }\end{array}$ \\
\hline $\begin{array}{l}\text { Hung } 2019 \\
{[36]}\end{array}$ & Level I RCT & 24 & $\begin{array}{l}68(66-72) \\
57 \% \text { female }\end{array}$ & $\begin{array}{l}\text { Xavi Sport VR } \\
6 \text { weeks }\end{array}$ & $\begin{array}{l}\text { Without } \\
\text { intervention }\end{array}$ & $\begin{array}{l}\text { TUG; BBS } \\
\text { UST; MFES }\end{array}$ & $\begin{array}{l}\text { VRT-NS group with positive effects } \\
\text { on functional balance. }\end{array}$ \\
\hline $\begin{array}{l}\text { Mugueta } \\
2019[42]\end{array}$ & Level I RCT & 40 & $\begin{array}{l}84(77-91) \\
60 \% \text { female }\end{array}$ & $\begin{array}{l}\text { Exergame } \\
\text { FRED } \\
6 \text { weeks }\end{array}$ & $\begin{array}{l}\text { Without } \\
\text { intervention }\end{array}$ & $\begin{array}{l}\text { BI; SPPB } \\
\text { EuroQol }\end{array}$ & $\begin{array}{l}\text { VRT-S reducing frailty risk: } 14.7 \% \\
\text { less control group. Not different } \\
\text { EuroQol or BI. }\end{array}$ \\
\hline $\begin{array}{l}\text { Stanmore } \\
2019[37]\end{array}$ & Level I RCT & 106 & $\begin{array}{l}78(58-96) \\
78 \% \text { female }\end{array}$ & $\begin{array}{l}\text { FAME } \\
\text { OTAGO } \\
12 \text { weeks }\end{array}$ & TSF & $\begin{array}{l}\text { BBS; FES } \\
\text { TUG; GDS }\end{array}$ & $\begin{array}{l}\text { VRT-S Exergame improved balance, } \\
\text { pain and fear of falling and are a } \\
\text { cost-effective fall prevention strategy } \\
\text { in assisted living facilities. }\end{array}$ \\
\hline
\end{tabular}


Table I. Continued

\begin{tabular}{|c|c|c|c|c|c|c|c|}
\hline Author & $\begin{array}{l}\text { Evidence level } \\
\text { Design }\end{array}$ & $n$ & $\begin{array}{l}\text { Age } \\
\text { (years)(SD), } \\
\text { range }\end{array}$ & $\begin{array}{l}\text { Experimental } \\
\text { group }\end{array}$ & Control group & $\begin{array}{l}\text { Outcome } \\
\text { measures }\end{array}$ & Results \\
\hline Tollar [43] & Level I RCT & 83 & $\begin{array}{l}69(66-72) \\
53 \% \text { female }\end{array}$ & $\begin{array}{l}\text { EXER-Xbox } \\
\text { or bicycle } \\
5 \text { weeks }\end{array}$ & $\begin{array}{l}\text { Usual routine } \\
\text { activities }\end{array}$ & $\begin{array}{l}\text { SF36; } \\
\text { 6MWT; } \\
\text { BERG; } \\
\text { SE-ADL }\end{array}$ & $\begin{array}{l}\text { VR Wii-Fit was feasible, acceptable, } \\
\text { and safe for frail older adults and } \\
\text { improved their postural control and } \\
\text { gait. There were no effects on } \\
\text { cognition, mood, or fear of falling. }\end{array}$ \\
\hline
\end{tabular}

ABC, Activities-specific Balance Confidence; ADL, Activities of Daily Living; AIDL, Activity Instrumental Daily Living; BI, Barthel Index; BBS, Balance Berg Scale; BE, Brain exercise; BI, Barthel Index; CAMCI, Computer Assessment of mild cognitive Impairment; CHAMPS, Community Healthy Activities Model Program for Seniors Questionnaire CSRQ, Cognitive Self-Report Questionnaire; CRST-RT, Choice Stepping Reaction Time; CS, Chair Stand; FES, Falls Efficacy Scale; FGA, Functional Gait Assessment; FIM, Functional Independence Measure; FPA, Foot Placement Accuracy; FR, Functional Reach; FSST, Four Square Step Test; GAS, Geriatric Anxiety Scale; GDS, Geriatric Depression Scale; IADL, Instrumental Activities of Daily living Scale; PRMQ, Prospective Retrospective Memory Questionnaire; MAQ, Modifiable Activity Questionnaire; MBI, Modified Barthel Index; MFES, Modified Falls Efficacy Scale; MMSE, Mini Mental State Examination; MoCA, Montreal Cognitive Assessment; MT, Movement Time; OPI, Overall Performance Index; PPA, Physiological Profile Assessment score; PACES, Physical Activity Enjoyment Scale; PE, Physical exercise; RAPA, Rapid Assessment Physical Activity Scale; SF8, Short Form; SF36, Short Form 36; RCT, Randomized Clinical Trial; SMWT, Six-Minute Walk Test; SPPB, Short Physical Performance Battery; TSF, Traditional senior fitness; TST, Ten Step Test; TUG, Timed Up and Go; UST, Unipedal Stance Test; VRT-S, Virtual Reality Technology Specific; VRT-NS,Virtual Reality Technology Non Specific; WHOQL-BREF, World Health Organization Quality of Life; 5STS, Five Times Sit-to-Stand.

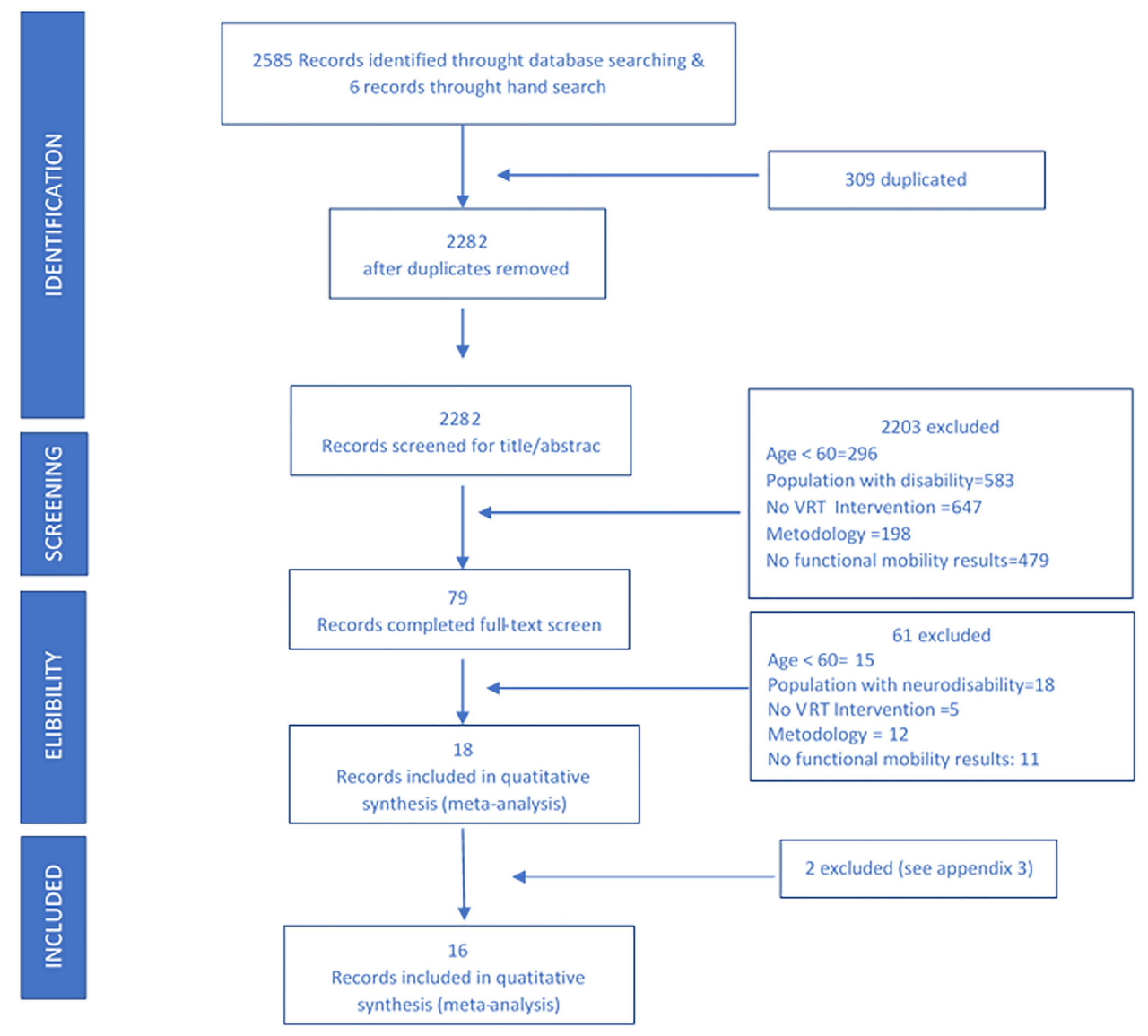

Figure 1. PRISMA flow diagram.

\section{Effect of VRT on functional mobility}

Figure 2 presents the meta-analysis of VRT-S and VRT-NS versus conventional treatment and versus no treatment for the TUG test. The analysis of the data revealed important differences between VRT-S and VRT-NS. In the studies using VRT-S, no differences were found when compared with a conventional intervention $(\mathrm{SMD}=0.0 ; 95 \% \mathrm{CI}$ -0.59 to 0.59 ) and the difference when compared with no intervention was minor (SMD $=-0.17 ; 95 \% \mathrm{CI}-0.52$ to $0.39)$. Nevertheless, VRT-NS was significantly more effective than no intervention in improving TUG scores (SMD $1.02 ; 95 \% \mathrm{CI}-1.91$ to -0.14$)$. As regards comparison with 


\section{A. I. Corregidor-Sánchez et al.}

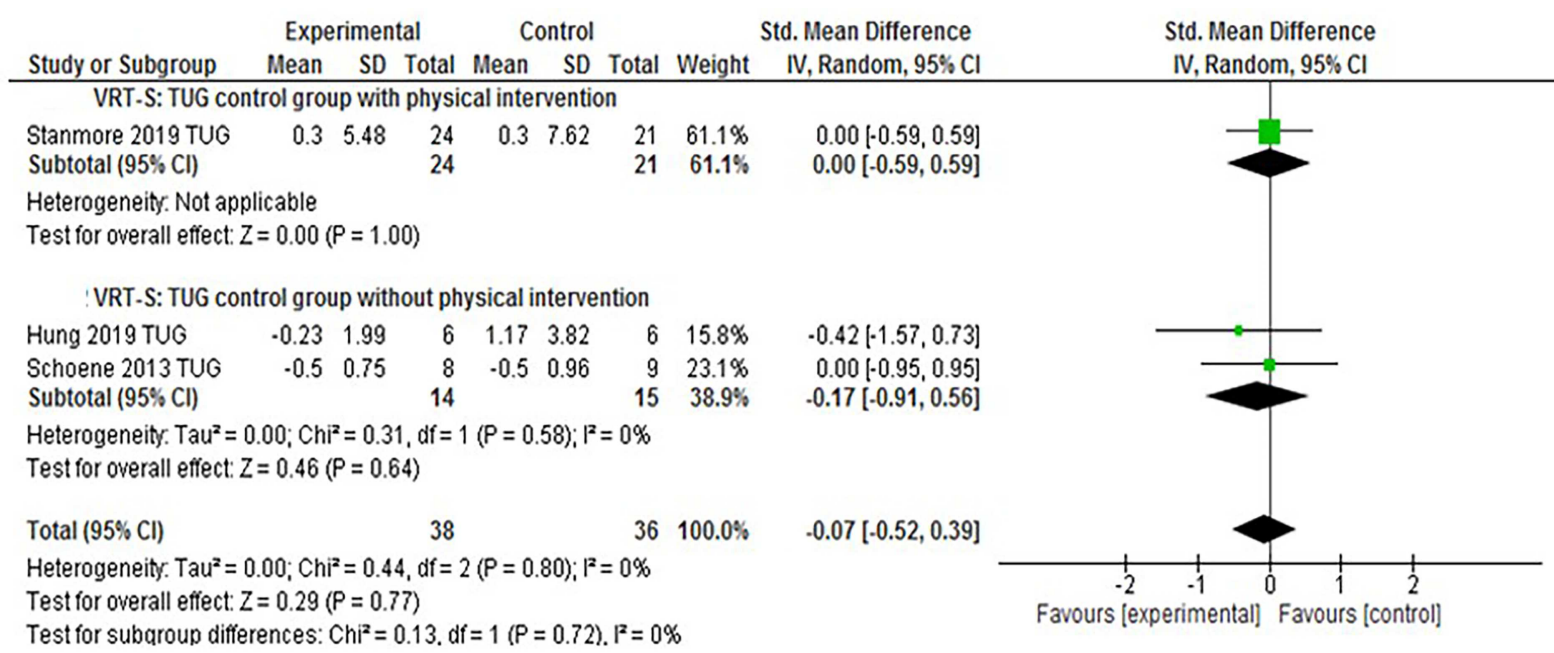

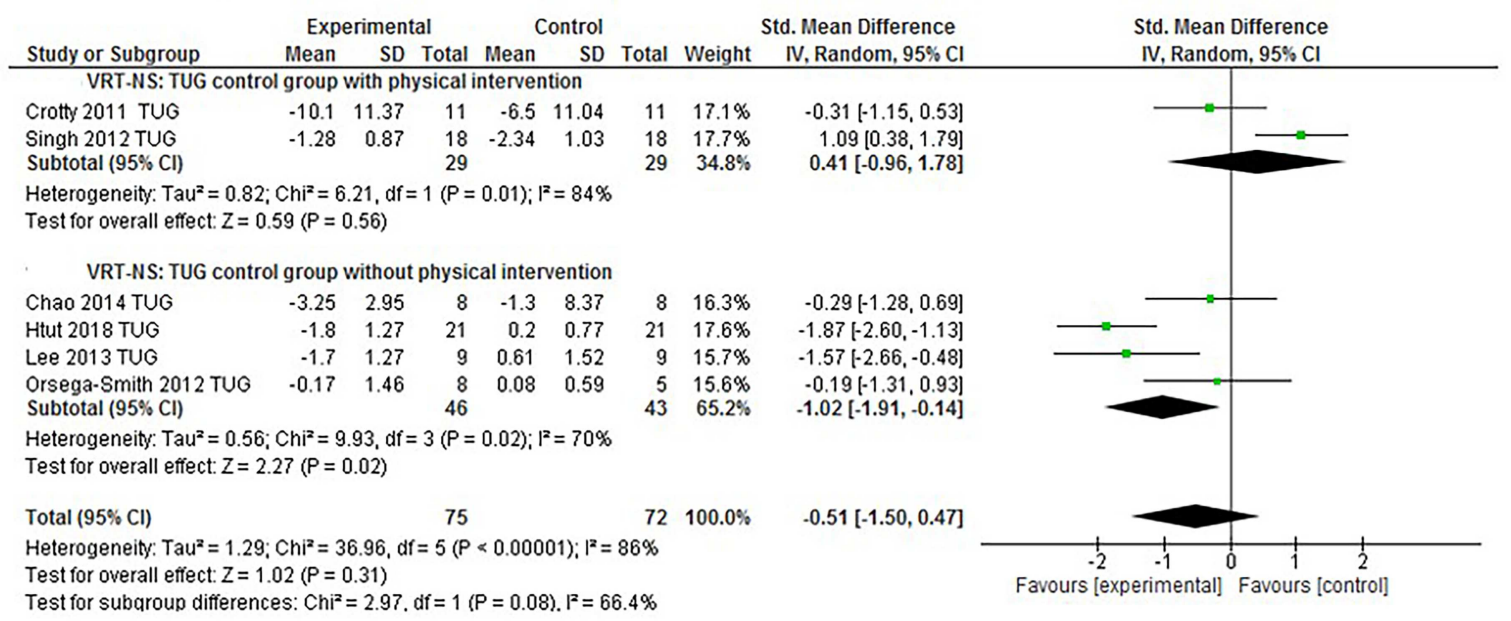

CI: confidence Interval; SMD: standarized mean difference; VRT-S: virtual reality Technology Specific; VRT-NS: virtual reality technology no specific

Figure 2. (a) Forest plot meta-analysis of VRT-S versus conventional interventions and versus no treatment for the Timed Up Go Test. (b) Forest plot meta analysis of VRT-NS versus conventional interventions and versus no treatment for the Timed Up Go Test.

standard therapy, VRT-NS had a moderate to low effect on the TUG test (SMD $-0.41 ; 95 \% \mathrm{CI}-0.96$ to -1.78 ).

Four studies with VRT-NS reported results on longdistance walking endurance with the 6MWT. Appendix 5 shows the meta-analysis of VRT-NS (6MWT) versus conventional treatment and versus the inactive control group. VRT-NS was clearly superior to conventional therapy for improving walking endurance (SMD - 1.20; 95\% CI - 1.93 to -0.46$)$. Positive benefits were also found when compared with inactive control (DME $=0,71 ; 95 \% \mathrm{CI}-2.16$ to $0.73)$. VRT-S and VRT-NS could not be compared in the 6MWT.

\section{Duration of the intervention}

Studies were grouped according to the duration of the intervention (Figure 3). No differences were found between groups when the treatment duration was $\leq 18$ sessions (SMD $0.04 ; 95 \% \mathrm{CI}-0.51$ to 0.95$)$. Studies with treatment duration of $>18$ sessions showed positive benefits for the TUG test (SMD -1.16; 95\% CI -2.33 to-0.01) and for 6MWT (SMD $-1.11 ; 95 \% \mathrm{CI}-1.91$ to -0.30$)$ versus no intervention (SMD $-0.89 ; 95 \% \mathrm{CI}-1.71$ to -0.08 ).

Those studies with $>18$ treatment sessions showed a decrease of $4.9 \mathrm{~s}$ in TUG (SMD -4.9; $95 \% \mathrm{CI}-6.95$ to 3.03; $P<0.01$ ) and an increase of $109 \mathrm{~m}$ in the 6MWT (SMD 109.5; 95\% CI 152.4-66.61; $P<0.01$ ). Both scores exceed the minimal clinically important differences (MCIDs) identified in studies in older adults, being $0.9-1.1$ in the TUG test $[45,46]$ and $30.5-70$ in the 6MWT $[47,48]$. This comparison was performed based on eight studies $[14,17,33,34,35,36,39,49]$ for the TUG test and four studies for the 6MWT [39, 40, 41, 43], with 113 participants for the VRT group and 108 participants for 


\begin{tabular}{|c|c|c|c|c|c|c|c|c|c|}
\hline \multirow[b]{2}{*}{ Study or Subgroup } & \multicolumn{3}{|c|}{ Experimental } & \multicolumn{3}{|c|}{ Control } & \multicolumn{2}{|r|}{ Std. Mean Difference } & \multirow{2}{*}{$\begin{array}{l}\text { Std. Mean Difference } \\
\text { IV, Random, } 95 \% \mathrm{Cl}\end{array}$} \\
\hline & Mean & SD & Total & Mean & SD & Total & Weight & IV, Random, $95 \% \mathrm{Cl}$ & \\
\hline \multicolumn{9}{|c|}{ s18 VRT treatment sessions: control group with physical intervention } & \\
\hline Crotty 2011 TUG & -10.1 & 11.37 & 11 & -6.5 & 11.04 & 11 & $18.7 \%$ & $-0.31[-1.15,0.53]$ & \\
\hline Singh 2012 TUG & -1.28 & 0.87 & 18 & -2.34 & 1.03 & 18 & $21.5 \%$ & $1.09[0.38,1.79]$ & \\
\hline Subtotal $(95 \% \mathrm{Cl})$ & & & 29 & & & 29 & $40.3 \%$ & $0.41[-0.96,1.78]$ & \\
\hline \multicolumn{10}{|c|}{$\begin{array}{l}\text { Heterogeneity: } \text { Tau }^{2}=0.82 ; \mathrm{Chi}^{2}=6.21, \mathrm{df}=1(P=0.01) ; \mathrm{I}^{2}=84 \% \\
\text { Test for overall effect: } Z=0.59(P=0.56)\end{array}$} \\
\hline \multicolumn{10}{|c|}{$<18$ VRT treatment sessions: control group without physical intervention } \\
\hline Chao 2014 TUG & -3.25 & 2.95 & 8 & -1.3 & 8.37 & 8 & $16.1 \%$ & $-0.29[-1.28,0.69]$ & \\
\hline Hung 2019 TUG & -0.23 & 1.99 & 6 & 1.17 & 3.82 & 6 & $13.5 \%$ & $-0.42[-1.57,0.73]$ & \\
\hline $\begin{array}{l}\text { Orsega-Smith } 2012 \text { TUG } \\
\text { Subtotal }(95 \% \mathrm{CI})\end{array}$ & -0.17 & 1.46 & $\begin{array}{r}8 \\
22\end{array}$ & 0.08 & 0.59 & $\begin{array}{r}5 \\
19\end{array}$ & $\begin{array}{l}14.0 \% \\
43.6 \%\end{array}$ & $\begin{array}{l}-0.19[-1.31,0.93] \\
-0.30[-0.92,0.32]\end{array}$ & \\
\hline \multicolumn{10}{|c|}{$\begin{array}{l}\text { Heterogeneity: } \operatorname{Tau}^{2}=0.00 ; C h i^{2}=0.08, \mathrm{df}=2(P=0.96) ; I^{2}=0 \% \\
\text { Test for overall effect: } Z=0.95(P=0.34)\end{array}$} \\
\hline \multicolumn{10}{|c|}{ - $\quad<18$ VRT treatment sessions: control group without physical intervention } \\
\hline $\begin{array}{l}\text { Chao } 20146 \mathrm{MWT} \\
\text { Subtotal }(95 \% \mathrm{Cl})\end{array}$ & -22.62 & 56.63 & $\begin{array}{l}8 \\
8\end{array}$ & -21.1 & 56.82 & $\begin{array}{l}8 \\
8\end{array}$ & $\begin{array}{l}16.2 \% \\
16.2 \%\end{array}$ & $\begin{array}{l}-0.03[-1.01,0.95] \\
-0.03[-1.01,0.95]\end{array}$ & \\
\hline \multicolumn{10}{|c|}{$\begin{array}{l}\text { Heterogeneity: Not applicable } \\
\text { Test for overall effect: } Z=0.05(P=0.96)\end{array}$} \\
\hline Total $(95 \% \mathrm{Cl})$ & & & 59 & & & 56 & $100.0 \%$ & $0.04[-0.51,0.59]$ & \\
\hline \multicolumn{9}{|c|}{$\begin{array}{l}\text { Heterogeneity: } \text { Tau }^{2}=0.23 ; \mathrm{Chi}^{2}=10.13, \mathrm{df}=5(P=0.07) ;\left.\right|^{2}=51 \% \\
\text { Test for overall effect: } Z=0.15(P=0.88) \\
\text { Test for subaroup differences: } \mathrm{Chi}^{2}=0.93, \mathrm{df}=2(P=0.63), \mathrm{I}^{2}=0 \%\end{array}$} & $\begin{array}{ccccc}-2 & -1 & 0 & 1 & 2 \\
\text { Favours [experimental] } & \text { Favours [control] }\end{array}$ \\
\hline
\end{tabular}

Test for subaroup differences: $\mathrm{Chi}^{2}=0.93, \mathrm{df}=2(\mathrm{P}=0.63) . \mathrm{I}^{2}=0 \%$

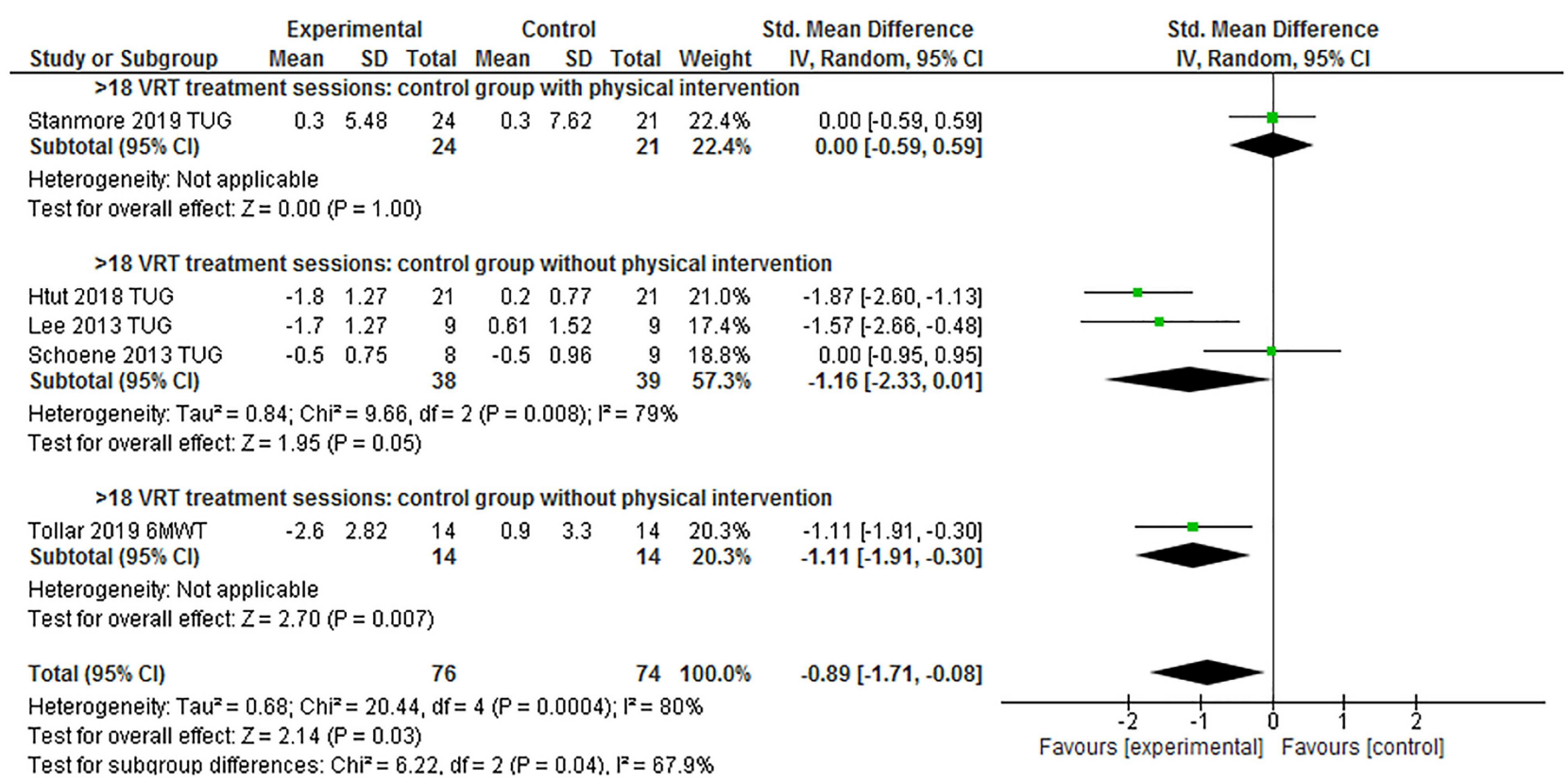

Figure 3. (a) Forest plot meta-analysis result for effectiveness of VRT $\leq 18$ treatment sessions. (b) Forest plot meta-analysis result for effectiveness of VRT $>18$ treatment sessions.

the experimental group. There was only one study with $>18$ sessions of treatment versus standard therapy [37], in which no clinically important differences were found $(\mathrm{SMD}=0.00 ; 95 \% \mathrm{CI}-0.59$ to 0.59$)$.

\section{Risk of bias}

The risk of bias analysis revealed that $83 \%$ of the studies had an adequate procedure of generating randomisation sequences, but only $23 \%$ reported allocation concealment appropriately. The blinding of the assessment was adequate in $35 \%$ of the studies and, with the exception of one study [12], all had a low risk of bias in the incomplete results (Figure 4). Heterogeneity was moderate $\left(I^{2}=56 \%\right)$.

\section{Publication bias}

In the Doi Plot and Funnel Plot, no significant publication bias was observed (Appendix 6). The LFK index was -0.96 


\begin{tabular}{|c|c|c|}
\hline Study or Subaroun & Risk of Bias & \\
\hline Chao 2014 & ? ? ? & \\
\hline Crotty 2011 & † ? $\odot ?$ & \\
\hline Daniel 2012 & †? ? †? & \\
\hline Farzin 2018 & 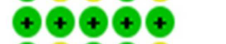 & \\
\hline Htut 2018 & † ?†? ? & \\
\hline Hughes 2014 & †?? ? ? & \\
\hline Hung 2019 & †? ? & $\square$ Low risk of bias \\
\hline Keogh 2014 & $\Theta \Theta \Theta ?$ & $\square$ Unclear risk of bias \\
\hline Lee 2013 & †? ? †? & $\square$ High risk of bias \\
\hline Maillot 2012 & †? ? †? & \\
\hline Mugueta 2019 & †? ? ? ? & \\
\hline Orsega-Smith 2012 & $\odot ?+?$ & \\
\hline Schoene 2013 & 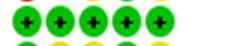 & \\
\hline Singh 2012 & †? ? †? & \\
\hline Stanmore 2019 & †૯૯૯ & \\
\hline Tollar 2019 & † ?†? ? & \\
\hline Vieira 2018 & 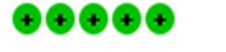 & \\
\hline Total $(95 \% \mathrm{Cl})$ & 0 & \\
\hline \multicolumn{3}{|c|}{ Heterogeneity: Not applicable } \\
\hline \multicolumn{3}{|c|}{ Risk of bias legend } \\
\hline \multirow{2}{*}{\multicolumn{3}{|c|}{$\begin{array}{l}\text { (A) Random sequence generation (selection bias) } \\
\text { (B) Allocation concealment (selection bias) }\end{array}$}} \\
\hline & & \\
\hline \multicolumn{3}{|c|}{ (C) Blinding of outcome assessment (detection bias) } \\
\hline \multicolumn{3}{|c|}{ (D) Incomplete outcome data (attrition bias) } \\
\hline (E) Selective reporting (report & g bias) & \\
\hline
\end{tabular}

Figure 4. Risk of bias.

for VRT-S and -0.27 for RVT-NS, the Egger test was 0.3 (VRT-S) and 0.3 (VRT-NS) and the Begg test was 0.3 (VRTS) and 0.012 (VRT-NS).

\section{GRADE analysis}

The GRADE analysis (Appendix 7) indicated a high quality of evidence for the impact of a VRT-S on functional mobility, which means that there is confidence that the true effect is close to the estimate of the effect. In the case of VRT-NS, the GRADE analysis indicated a low quality of the evidence, indicating that our confidence in the estimate of the effect is limited; the true effect may be substantially different from the estimate of the effect found in this meta-analysis.

\section{Discussion}

This meta-analysis assessed the effectiveness and quality of evidence from VRT programmes aimed at improving functional mobility in individuals over 60 years of age. To our knowledge, this is the first meta-analytical review which differentiates and compares the two major types of VRT (VRT-S and VRT-NS) versus conventional therapy or no intervention. Most of the studies showed that intervention with VRT had positive and significant effects on functional mobility.

The comparison between VRT-S and VRT-NS showed results in favour of VRT-NS in improving functional mobility. VRT-NS proved to have significant benefits when compared with no intervention $(\mathrm{SMD}=-1.02)$ and benefits slightly superior to conventional therapy $(\mathrm{SMD}=0.41)$. VRT-S had similar results to conventional therapy and no benefits were found when compared with no intervention $(S M D=-0.17)$. It follows from these data that VRT-NS may be more beneficial than VRT-S in improving functional mobility in healthy older people.

Our results were unexpected, because it is usual to think that VRT-S systems are better prepared and adapted to rehabilitate mobility, so they should be more effective. Previous reviews have confirmed this in older people with stroke [20]. However, when there is no disability, it is likely that benefits are also obtained from more global virtual activities such as those offered by VRT-NS teams. Players prefer highly realistic games (e.g. sport exergames) and games that are intuitive (in terms of body movement and controls) compared with rehabilitation exercises $[50,51]$. Older user-friendly exergames combined with game-based extrinsic motivation have a large potential to motivate older adults to change their sedentary lifestyle and perform exercises [10]. Authors such as Lee [38] or Straudi [52] argue that exergames increase adherence versus traditional rehabilitation techniques.

The TUG test and the 6MWT were used in order to determine the impact of VRT on functional mobility. Our estimation showed a $4 \mathrm{~s}$ reduction in TUG and a $94 \mathrm{~m}$ increase in 6MWT in studies with a duration of treatment of $>18$ sessions and an inactive control. These results exceed the MCID which has been set at $0.9-1.14 \mathrm{~s}$ for the TUG test $[46,47]$ and $30-70 \mathrm{~m}$ for the 6MWT $[47,48]$. Previous reviews also found a decrease of $1.20 \mathrm{~s}$ when the duration of the treatment with VRT-NS was 12 weeks. It seems plausible to deduce that VRT could contribute to maintaining independence in activities of daily living and delaying functional decline and the need for support.

The interpretation of these data needs to be done with care and be considered in the context of the lack of data to support the true size of the effect. Allocation concealment and the blinding of the assessment were not clear in most of studies using VRT-NS, that is why the results obtained may lead to a higher effect estimate. The four trials using VRT$S$ reported the sequence of randomization and blinding in a clearer way, presenting less risk of bias and therefore a greater reliability in the estimate of effect, but studies with VRT-NS had important methodological limitations, which have also been found in previous reviews $[53,54,55]$. So, we suggest for future studies on VRT-S to design protocols that include the control of possible confounding factors and the planning of follow-up.

Regarding the quality of evidence, the application of the GRADE system indicated that the degree of recommendation of the VRT-S to improve the functional mobility of older people is high, while the quality of evidence of the VRT-NS test suite is low. This result suggests the need to make an effort to address methodological limitations, with more robust RCTs and a methodological planning that includes masking of participants, blinding of assessors and the concealment of the randomization sequence in 
order to know the true effect size of the different types of VRT. As for the limitations of this review, first, we may not have identified all studies despite using comprehensive search strategies. Secondly, we included only older people without disabilities, so the results cannot be generalised to older adults with established disabilities such as those with neurological or musculoskeletal diseases. Finally, the methodological weaknesses of many studies and the lack of follow-up after the intervention prevent us from knowing whether the effect achieved with VRT is long lasting.

\section{Conclusion}

Our findings suggest that VRT interventions have positive effects on functional mobility compared with conventional treatment or no intervention. VRT-NS had a greater effect than VRT-S. Results were significant in studies with a duration of $>18$ sessions versus no intervention. Nevertheless, due to the high risk of bias and the low quality of the GRADE evidence, these results are inconclusive.

\section{Declaration of Conflicts of Interest: None.}

Declaration of Sources of Funding: None.

\section{References}

A full list of 56 reference can be found in Appendix 8.

1. Gitlin L. Conducting research on home environments. lessons learned and new directions. Gerontologist 2003; 43: 628-37.

2. van Rijckevorsel-Scheele J, Willems RCWJ, Roelofs PDDM, Koppelaar E, Gobbens RJJ, Goumans MJBM. Effects of health care interventions on quality of life among frail elderly: a systematized review. Clin Interv Aging 2019; 14: 643-58.

3. Lange BS, Requejo P, Flynn SM et al. The potential of virtual reality and gaming to assist successful aging with disability. Phys Med Rehabil Clin N Am 2010; 21: 339-56.

4. Forum OTP. Domain and process (3rd edition). Am J Occup Ther 2014; 68: S1-48.

5. Estrategia Nacional de Personas Mayores para un Envejecimiento Activo y para su Buen Trato. 2018.

6. Health survey for England. London: Natcen Social Research, 2017.

7. Laffon de Mazières C, Morley JE, Levy C et al. Prevention of functional decline by reframing the role of nursing homes? J Am Med Dir Assoc 2017; 18: 105-10.

8. Daniels R, van Rossum E, Metzelthin $S$ et al. A disability prevention programme for community-dwelling frail older persons. Clin Rehabil 2011; 25: 963-74.

9. Kappen DL, Mirza-Babaei P, Nacke LE. Older adults' physical activity and Exergames: a systematic review. Int J HumanComputer Interact 2019; 35: 140-67.

10. Hasselmann V, Oesch P, Fernandez-Luque L, Bachmann S. Are exergames promoting mobility an attractive alternative to conventional self-regulated exercises for elderly people in a rehabilitation setting? Study protocol of a randomized controlled trial. BMC Geriatr 2015; 15: 108.

11. Karssemeijer EGA, Aaronson JA, Bossers WJ, Smits T, Olde Rikkert MGM, Kessels RPC. Positive effects of combined cognitive and physical exercise training on cognitive function in older adults with mild cognitive impairment or dementia: a meta-analysis. Ageing Res Rev 2017; 40: 75-83.

12. Keogh JWL, Power N, Wooller L, Lucas P, Whatman C. Physical and psychosocial function in residential aged-care elders: effect of Nintendo Wii sports games. J Aging Phys Act 2014; 22: 235-44.

13. Rendon AA, Lohman EB, Thorpe D, Johnson EG, Medina $\mathrm{E}$, Bradley $\mathrm{B}$. The effect of virtual reality gaming on dynamic balance in older adults. Age Ageing 2012; 41: 549-52.

14. Orsega-Smith E, Davis J, Slavish K, Gimbutas L. Wii fit balance intervention in community-dwelling older adults. Games Health J 2012; 1: 431-5.

15. Gomes GCV, Bacha JMR, do Socorro Simóes M et al. Feasibility, safety, acceptability, and functional outcomes of playing Nintendo Wii fit plus ${ }^{\mathrm{TM}}$ for frail elderly: study protocol for a feasibility trial. Pilot Feasibility Stud 2017; 3: 41.

16. Virk S, McConville KMV. Virtual reality applications in improving postural control and minimizing falls. Conf Proc IEEE Eng Med Biol Soc 2006; 1: 2694-7.

17. Singh DKA, Rajaratnam BS, Palaniswamy V, Raman VP, Bong PS, Pearson H. Effects of balance-focused interactive games compared to therapeutic balance classes for older women. Climacteric 2012; 16: 141-6.

18. Duque G, Boersma D, Loza-Diaz G et al. Effects of balance training using a virtual-reality system in older fallers. Clin Interv Aging 2013; 8: 257-63.

19. Suárez H, Suárez A, Lavinsky L. Postural adaptation in elderly patients with instability and risk of falling after balance training using a virtual-reality system. Int Tinnitus J 2006; 12: $41-4$.

20. Maier M, Rubio Ballester B, Duff A, Duarte Oller E, Verschure PFMJ. Effect of specific over nonspecific VR-based rehabilitation on poststroke motor recovery: a systematic meta-analysis. Neurorehabil Neural Repair 2019; 33: 112-29.

21. Guyatt G, Oxman AD, Akl EA et al. GRADE guidelines: 1. Introduction-GRADE evidence profiles and summary of findings tables. J Clin Epidemiol 2011; 64: 383-94.

22. World Health Organization. International classification of functioning, disability and health: ICF. Geneva: World Health Organization, 2001.

23. WHO | Physical Activity. WHO http://www.who.int/die tphysicalactivity/pa/en/ (date last accessed 19 March 2020).

24. RevMan 5 | Cochrane Community. /help/tools-and-software/revman-5 (date last accessed 28 April 2018,).

25. Higgins JPT, Altman DG, Gotzsche PC et al. The Cochrane Collaboration's tool for assessing risk of bias in randomised trials. BMJ 2011; 343: d5928-8.

26. Cohen J. Statistical Power Analysis for the Behavioral Sciences. 2nd edition. Hillsdale, NJ: Lawrence Erlbaum Associates, 1988.

27. Egger M, Smith GD, Schneider M, Minder C. Bias in metaanalysis detected by a simple, graphical test. BMJ 1997; 315 : 629-34.

28. Epidat 3.1. https://www.sergas.es/Saude-publica/Documents/ 1918/Ayuda\%20General.pdf (date last accessed 26 October 2018). 


\section{A. I. Corregidor-Sánchez et al.}

29. Furuya-Kanamori L, Barendregt JJ, Doi SAR. A new improved graphical and quantitative method for detecting bias in meta-analysis. Int J Evid Based Healthc 2018.

30. Montero-Alía P, Miralles-Basseda R, López-Jiménez $\mathrm{T}$ et al. Controlled trial of balance training using a video game console in community-dwelling older adults. Age Ageing 2019; 48: $506-12$.

Received 18 December 2019; editorial decision 3 August 2020 